Vantage: Journal of Thematic Analysis

ISSN: 2582-7391

A Multidisciplinary Publication of Centre for Research,

Maitreyi College, University of Delhi

April 2020, Volume 1, Issue 1

Research Communication

\title{
Carbon Footprint as Climate Change Disclosure: Opportunities for Performance Improvement
}

\author{
Haritma Chopra ${ }^{1}$, Pooja Goel ${ }^{2}$, Tuisem Shimrah ${ }^{2}$, Pinkey Bajaj Gandhi ${ }^{1}$, Veena Ghuriani ${ }^{1}$ \\ and Pooja Baweja*1 \\ ${ }^{1}$ Maitreyi College, University of Delhi, New Delhi - 110021 \\ ${ }^{2}$ University School of Environment Management, Guru Gobind Singh Indraprastha \\ University, New Delhi - 110075 \\ *Corresponding author: poojabaweja@gmail.com
}

\begin{abstract}
Carbon Footprint refers to the potential climate impact (Global Warming) due to Greenhouse Gases (GHG) emitted directly or indirectly owing to an organization's activities. A climate change disclosure of any educational institution must be studied so that its key emission sources can be identified and necessary mitigation measures be adopted for carbon reduction. An assessment based on the same was carried out at Maitreyi College, a constituent of the University of Delhi. The emissions were reported from college-owned facilities, indirect energy emissions from electricity, travel and solid waste generation. Consequently, some measures for efficient power consumption and management of waste were suggested to the college management in order for them to set a target for carbon reduction in the upcoming years. The benefits of the project will manifest in substantial utility cost reduction across the campus in the coming years, and will lead to both financial as well as environmental sustainability of the institution.
\end{abstract}

Keywords: Carbon footprint, GHG emission, Scopes, GHG protocol, sustainability

Abbreviations: CFP (Carbon Footprint), CNG (Compressed Natural Gas), DG (Diesel Generator),e (equivalent), GHG (Greenhouse Gas), IPCC (Inter-Governmental Panel on Climate Change), LPG (Liquefied petroleum gas),t (ton), WBCSD (World Business Council for Sustainable Development), WRI (World Resource Institute).

\section{INTRODUCTION}


Global warming is one of the most pertinent concerns being faced by the world today. The most immediate and evident effect of global warming is the increase in average global temperature. The emission of Greenhouse Gases (GHGs) is adjudicated as one of the primary causes for global warming (IPCC, 2006). Quantifying these GHG emissions, owing to various anthropogenic activities, is the primary step towards the reduction of emissions and reducing the probability of disaster in the future. Carbon Footprint (CFP) helps to identify major sources of GHG emissions which can be used as an indicator of climate performance (Wiedman \& Minx, 2008). It can be calculated for an institute and used as a tool to measure the required emission reduction. According to Carbon Trust (2007), "Carbon Footprint is defined as a measurement of the total GHG emissions caused directly and indirectly by an individual, an organization, event or product and is expressed as a carbon dioxide equivalent $\left(\mathrm{CO}_{2} \mathrm{e}\right)$ "'.

An organizational carbon footprint calculates the GHG emissions measuring all activities within the organization- such as energy used across buildings, various fugitive emissions, industrial activities and automobiles in a company. In addition, measuring an organization's total GHG impression, CFP exploration provides the organization with a GHG record which is comprehensive, and can be used to identify major emission sources to reduce them. Various organizations such as Fire Services, Food industries, Service industry, Universities, and Hospitals estimate their carbon footprint now-a-days (Mahanama \& Navaratne, 2018). To assess the local GHGs emissions and carbon foot-printing, actions need to be taken which are computable and certifiable. In the present study, data was collected at Maitreyi College, University of Delhi, for assessing the Carbon Footprint, by identifying GHGs emissions from various activities carried out at the campus. Visits were carried out to collect data for the Scope 1, 2 and 3 sources of GHG emissions as per the Greenhouse Gas Protocol, India, developed by WRI and WBCSD. The report highlights the current key emission sources of the college and sets a baseline data for setting up college-wide emission reduction targets for the upcoming financial years. The report also suggests some measures to reduce the carbon footprint.

\section{MATERIALS AND METHODS}

The data was collected in three phases: Planning, Data Collection and Estimation of $\mathrm{CO}_{2}$, followed by suggestive measures for reduction. The research was initiated to effect better management, post which a core team was constituted (comprising teachers and students from different departments). Several site visits and face-to-face interactions were done with various departments to collect the required data which helped in identifying the key emission sources across the campus. The study included extensive research on latest emission factors for 
computing the footprint, for which both qualitative and quantitative data was collected. All these primary and secondary sources were explored to extract the data necessary for the study. Data of fugitive emissions from the installed air conditioners and refrigerators, LPG consumption in the canteen and chemistry laboratory, diesel consumption in DG, etc. was collected with the help of quotations/invoices/record registers. A detailed methodology as per the guidelines of GHG Protocol, India, along with several recognized national and international standards, were referred to for computation of the footprint of the college. The software "Agile CF Toolkit (C) Agile Group" was used for the calculation of $\mathrm{CO}_{2}$ equivalent. This software uses the latest applicable emission factors sourced from published reliable databases for specific country of computation.

\section{RESULTS AND DISCUSSIONS}

Maitreyi College, through this project, has reported on its scope 1, 2 and 3 carbon emissions, emerging as the first college in Delhi University to undergo carbon disclosure. These emissions were reported from college-owned facilities and indirect energy emissions of purchased electricity, as well other indirect emissions, like paper consumption, commuting of students and employees, etc. Outcomes from other college activities (but not under the direct control of the college) were also assessed. Further, a Scope-wise comparison was done and it was found that Scope 2 GHG emission (purchased electricity) was the major contributor to the institution's carbon footprint. This was because of the lack of awareness regarding energy savings and absence of energy-efficient technologies across the campus. Scope 3 emissions were computed to be the second major contributor to GHG emissions of the college. The same was analyzed for commuting activities of the college, paper consumption and generation of garden waste throughout the year. The least significant emissions were reported from Scope 1 emission sources which comprised of LPG consumption, CNG using fugitive emissions, etc. Under the same, emissions due to LPG were found to be most significant.

The total carbon emission of the college was computed to be 482 tons of $\mathrm{CO}_{2} \mathrm{e}$. Major emissions in scope 2 were estimated to be 266.91 tons CO2e. Scope 3 emissions were calculated to be 202.50 tCO2e and minimum emissions were in scope 1 i.e. $12.58 \mathrm{CO} 2 \mathrm{e}$ (Table 1). Details of the data are also available at http://maitreyi.ac.in/default.aspx.

The maximum carbon emissions of the total emissions calculated were due to consumption of purchased electricity $(55.37 \%)$. This is followed by emissions from the commuting of 
employees and students (42.02\%). However, Scope 1 contributed only $2.6 \%$ to the total emissions (Figure 1).

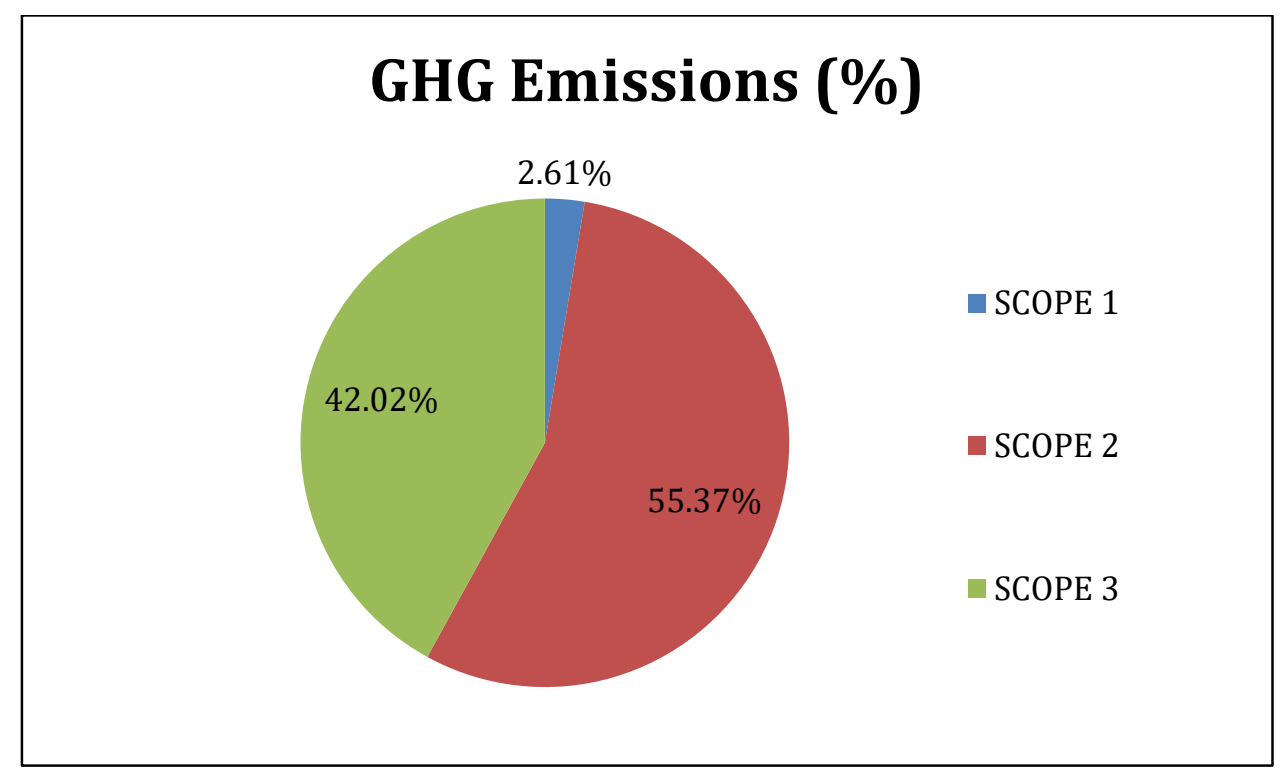

Figure 1: GHG Emissions of Maitreyi College (\%)

Table 1: Estimated CF of Maitreyi College for the Reporting Year 2018-19

\begin{tabular}{|c|c|c|c|c|c|c|c|c|c|}
\hline $\begin{array}{c}\text { GHG } \\
\text { Emissions }\end{array}$ & \multicolumn{4}{|c|}{ Scope 1} & Scope 2 & \multicolumn{3}{|c|}{ Scope 3} & Total \\
\hline \multirow{2}{*}{$\begin{array}{l}\text { Total } \\
\mathrm{kgCO}_{2} \mathrm{e}\end{array}$} & $\begin{array}{l}\text { LPG } \\
\text { Consumption }\end{array}$ & $\begin{array}{l}\text { Diesel } \\
\text { Consumption }\end{array}$ & $\begin{array}{l}\text { Mobile } \\
\text { Source } \\
\text { emission }\end{array}$ & $\begin{array}{l}\text { Fugitive } \\
\text { Emissions }\end{array}$ & $\begin{array}{l}\text { Purchased } \\
\text { Electricity }\end{array}$ & Commuting & $\begin{array}{l}\text { Paper } \\
\text { Consumption }\end{array}$ & $\begin{array}{l}\text { Garden } \\
\text { Waste }\end{array}$ & $\left(\mathrm{kgCO}_{2} \mathrm{e}\right)$ \\
\hline & $6,744.82$ & $5,135.73$ & 11.94 & 695.60 & $2,66,910.98$ & $1,91,957.2$ & $10,554.64$ & 6 & $4,82,006.88$ \\
\hline
\end{tabular}

Various mitigation measures were suggested by the research team to the college management post assessment, like formulation of the college's environmental policy, formation of Greenhouse gas Information Management System (including teachers, non-teaching staff and students from various departments), use of energy labelled equipment (e.g. all-in-one monitors, star labelled air conditioners, refrigerators, printing machines, etc.) across the campus, Green Labelling of Departments, use of biogas as a secondary source of energy for garden activities or other small utilities across the campus, installation of solar panels, recycling of e-waste, etc. (Ramachandra, 2012). Implementation of the suggestive measures, development of an Environment Policy by the college management, and regular monitoring and reviews by the 
carbon Management team can help the college achieve its set target for carbon reduction in the upcoming years.

\section{CONCLUSION}

Maitreyi College, through this pioneering study, will motivate other educational institutions to undertake similar disclosure projects and bring to the table innovative and cost-effective carbon reduction measures for the education sector. The benefits of the project will manifest in substantial utility cost reductions across the on-campus operations, and will lead to both financial as well as environmental sustainability of the college.

In this scenario, when global warming is an issue being confronted by the world, quantifying GHG emissions from various sectors is an imperative step towards the reduction of emissions and disaster. Carbon Footprint of all the institutions in the education sector can thus be an indicator, which will help the world achieve environmental sustainability in order to combat the climate-change crisis.

\section{CONFLICT OF INTEREST}

The authors declare that there is no conflict of interest regarding this research article.

\section{SOURCE OF FUNDING}

None

\section{ACKNOWLEDGEMENT}

The authors are highly thankful to the Agile Group, New Delhi, India for their constant support and help in calculating the carbon footprint of Maitreyi College, University of Delhi.

\section{REFERENCES}

Carbon Trust (2007). Carbon footprint measurement methodology, version 1.1. The Carbon Trust, London, UK. Available online at http://www.carbontrust.co.uk.

IPCC (2006). IPCC Guidelines for National Greenhouse Gas Inventories, 2006.Prepared by the National Greenhouse Gas Inventories, eds. H.S. Eggleston, L. Buendia, K Miwa, T Ngaraand K. Tanabe. IGES, Japan.

Mahanama, A. and Navaratne C.M. (2018). Carbon Footprint of an Organization: a Tool for Monitoring Impacts on Global Warming, Procedia Engineering 212: 729-735. 
Ramachandra, T.V. (2012). 'Decentralised carbon footprint analysis for opting climate change mitigation strategies in India', Renewable and Sustainable Energy Reviews, 16, $5820-5833$.

Weidman, T. and Minx, J. (2008). A Definition of 'Carbon Footprint'. In: C. C. Pertsova (ed.), Ecological Economics Research Trends (pp. 1-11), Nova Science Publishers, Hauppauge NY, USA.

How to cite this article: Chopra, H., Goel, P., Shimrah, T., Gandhi, P.B., Ghuriani, V. \& Baweja, P. (2020). Carbon Footprint as Climate Change Disclosure - Opportunities for Performance Improvement. Vantage: Journal of Thematic Analysis, 1(1), 161-166.

DOI: https://doi.org/10.52253/vjta.2020.v01i01.14

(C) The Author(s) 2020.

This work is licensed under a Creative Commons Attribution 4.0 International License which permits its use, distribution and reproduction in any medium, provided the original work is cited. 